\title{
Connecting landscapes with built environments: visibility analysis, scale and the senses
}

This paper reviews some of the main theoretical critiques of spatial technological approaches to the past, particularly of visibility analysis. It considers the extent to which methodologies for both the built environment and for wider landscapes might either reject or respond to these issues, considering in particular (a) the claim that such work is based on a culturally-specific concept of space (the map) that is unlikely to have been shared by other cultures in the past and (b) the accusation that analysis of visual structure perpetuates a western bias towards vision over the other senses and 'privileges' the visual over other aspects of perception and bodily engagement. The paper concludes that, although much of this critique can be contested or moderated in various ways, we should accept that vision is not easily separable from other senses. To respond to this challenge, it is suggested that we should seek a framework to understand the link between space and all the senses while at the same time seeking to bring together the traditions of spatial analysis for landscape archaeology and the built environment. One possible way forward may be to combine the sensory/spatial framework used by proxemics for smaller scales with that defined by Higuchi for landscapes because they share some useful concepts. It is hoped that responding positively in this way to postprocessual critique may ultimately enrich formal methods of understanding ancient urban environments and landscapes.

\section{Formal visibility analysis in archaeology}

Archaeological studies of the built environment have long shared with landscape-scale studies an interest in the visual structure of space, although these two scales of analysis have generally followed parallel methodological developments: landscape studies have evolved paper-based methods into GIS-based 'viewshed' analysis, while studies of built environments have developed methods based on 'isovists' or axial graph analysis (Hillier, this volume). These traditions of research share a number of methodological and theoretical aspects, but interestingly, while landscape-scale work has increasingly evoked specific theoretical criticism, work on the built environment has largely avoided such issues. If the positive trend towards convergence between landscape-scale and urban-scale studies of visual structure is to continue, therefore, it may be useful to review some of the theoretical concerns that have been raised and to explore how both approaches might respond to them. 
Spatial technologies are now well established in archaeological practice both for the management of archaeological remains and also as a platform for spatial analysis, while Geographic Information Systems (GIS) are now so established within archaeological practice that their use barely warrants specific mention. Their application to archaeology has been the subject of numerous papers and edited volumes (Westcott and Brandon 2000; Aldenderfer and Maschner 1996; Maschner 1996; Lock 2000; Lock and Stanèiè I995; Gillings et al. 1999; García Sanjuan and Wheatley 2002; Grau Mira 2006; Johnson and North I997) and at least three books (Wheatley and Gillings 2002; Connolly and Lake 2006; Chapman 2006). Initially seen as a tool with which to implement statistical models of site locations (Carr 1985; Kvamme I983; Kvamme 1989) or to re-cast functional-processual approaches to space such as site catchment analysis (Hunt I992; Gaffney and Stančič I99I), spatial computation has rapidly become the platform of choice for an array of intersite spatial analyses and formal approaches to landscape archaeology.

In the last decade or so, advocates of spatial technological approaches to archaeological landscapes have attempted to broaden the theoretical basis of their work at the same time as expanding its methodological sophistication, and in doing so have drawn on a range of both processual and postprocessual theoretical ideas. As part of this, particular attention has focused on the analysis of the visual structure of archaeological landscapes (Gillings and Wheatley 200I; Wheatley and Gillings 2000). Llobera (1996; I999), for example, has espoused an approach that draws on the ecological psychology of Gibson (I979) in the analysis of later prehistoric linear ditches in Wessex, and has subsequently broadened the conceptual basis of visibility analysis with the notion of the 'visualscape' (Llobera 2003), while Wheatley and Gillings (2000) have sought to re-situate visibility analysis as a humancentred methodology and incorporate aspects of the approach to landscape advocated by Higuchi (I988). Visibility analysis has now been used to analyse different aspects of many prehistoric landscapes, including the locations of 'cup and ring' petroglyph panels in the Kilmartin region of northwest Scotland (Gaffney et al. I996), the ritual landscape around Stonehenge (Exon et al. 2000), the settings of passage graves, 'tertres tumulaire' and 'allées coudées' of Brittany (Roughley 2004), the locations of Hungarian tells (Trick 2004) and the distribution of Neolithic and Calcolithic tombs in the eastern Sierra Morena, Andalusia (García Sanjuan et al. 2006). Influenced by the phenomenological approach of Tilley (I994) and Thomas (I99I; I996; I999), among others, it has also been deployed in parallel with non-computational methods, as in Cummings and Whittle's (2004) work on the landscape setting of megalithic monuments in Wales.

Computational analysis of visibility has a similarly long history in the analysis of the built environment, with methods based on 'isovists' (Batty 200I; Benedikt I979) having clear parallels with 'viewshed' analysis, while line-of-sight analyses are a major component of approaches based on Space Syntax (Hillier and Hanson 1984; Hillier, this volume), where they are often referred to as Visibility Graph Analysis (Turner et al. 200I) and have been used to investigate past as well as contemporary spaces (Clark 2007; Stavroulaki and 
Peponis 2005). These two traditions of visibility analysis within landscape archaeology and the built environment are perhaps now beginning to converge, as in the deployment of three-dimensional approaches to visibility that have been used to analyse the positioning and iconography of Theran frescoes (Paliou 2009; Paliou and Wheatley 2007; Paliou et al. 20II; Paliou, this volume; Papadopoulos and Earl, this volume), work which draws heavily on traditions of research both in architecture and landscape archaeology.

\section{Critiques of spatial technological approaches}

Perhaps as a result of its origins within functional-processual archaeology and the subsequent attempts to broaden the theoretical basis of the approach, the use of spatial technologies within landscape archaeology has attracted a more sustained attack from postprocessual or postmodern theorists within the discipline, with particular attention devoted to the development and use of formal methods for the analysis of visual structure in ancient landscapes. The nature of the critique that has been levelled against visibility analysis (and, more broadly, against the application of GIS to archaeology) is both complex and inhomogeneous, and it mirrors the wider schism that has emerged within archaeological theory over the last three decades between, on the one hand, scientific approaches to archaeological analysis (broadly processual, neo-processual or cognitivist) and on the other hand a range of theoretical positions generally referred to as 'postprocessual', which include post-structuralism, phenomenology, feminism and postmodernism. The latter are clearly diverse and not always compatible with each other, but it is reasonable to continue to regard them as, in some sense, a single school of thought, as they generally share the aim of revising or refuting one or more of the basic tenets of enlightenment philosophy and Cartesian thought on which 'scientific' approaches are based (cf. for example Hodder 200I; Johnson I999; Jones 200I; Trigger I989).

Without becoming embroiled in a broader theoretical debate that is well beyond the scope of this volume (and is, anyway, rather less bipartisan than it was a decade or so ago), two aspects of the critique levelled at spatial visibility analysis may be worthy of a considered response because they ask interesting questions about how we might go about understanding the spatial configuration of cultural remains from the past. The first arises from a widespread postmodern concern with the contextual nature of human experience, from which perspective the map-like, geometric idea of space that underpins formal spatial analysis is argued to be problematic because it is a modern, western construct that we cannot assume is/was shared by other cultures at other times. The second critique (which emerges largely from a phenomenological perspective) holds that an understanding of human experience should begin with corporeal engagement with the world, and that formal methods of visibility that separate out vision as a separate field of analysis artificially 'privilege' the visual over other aspects of bodily engagement, notably the other senses. 


\section{The map as a culturally-specific 'way of seeing'}

The first of these holds that computational approaches and formal spatial analyses are irredeemably built upon on an historically-specific concept of space - the map - which constitutes a specific way of 'looking at the world', one which is contested by, for example, phenomenological (e.g. Tilley I994) and feminist (e.g. Gidlow 2000; Haraway I99I) theorists.

For Thomas, for example, "the distribution map, the air photo, the satellite image, the Geographic Information System, are all distinctively specular. They all present a picture of past landscapes which the inhabitant would hardly recognise" and spatial technologies "attempt to lay the world bare ... like a corpse under the pathologist's knife" (I993, p. 25). He has also argued that this feminises and objectifies the landscape and that this way of looking constitutes an example of 'the male gaze'. Relating the map perspective of spatial technologies to Haraway's (I99I, p. 678) notion of a "god trick", he later claims that "such a sexualised way of looking is particularly troubling since we habitually make use of a series of spatial technologies (GIS, satellite imagery, air photography) which seek to lay bare and penetrate the land" (200I, p. I69).

It is, of course, debatable whether map-like spatial abstraction constitutes a specifically male way of imagining the world, as some feminist theorists have suggested, and even more questionable that it follows that 'scientific' spatial analysis should be regarded as some kind of landscape pornography (as Thomas appears to suggest). It is also not entirely clear that Haraway intended the 'god trick' quote to refer literally to maps in this way: the term actually emerges from a far wider discussion of situated knowledge and the limits of objectivity that is part of a much wider and more nuanced discourse on building a new kind of (feminist) science:

Vision is the technological feast becomes unregulated gluttony; all perspective gives way to infinitely mobile vision, which no longer seems just mythically about the god-trick of seeing everything from nowhere, but to have put the myth into ordinary practice. And like the god-trick, this eye fucks the world to make techno-monsters. (Haraway I99I, p. 678)

Nevertheless, there is no doubt that the perspective of GIS (and maps and orthophotography) is a very particular spatial abstraction that is - as has been claimed - a way of imagining space as if looking down from above, although, contrary to Thomas' claim (following Cosgrove I984) that this modern idea of landscape emerges with the adoption of linear perspective in art, it is an abstraction that eschews any representation of perspective. While accepting this, however, the assumption that inhabitants of past landscapes would "hardly recognise" a top-down, map-like representation of the world is contestable. There are actually many reasons to suspect that many non-western, non-modern cultures are and were capable of this kind of spatial abstraction, not least that maps themselves have a surprisingly long history (Harley and Woodward I987). The capacity to represent space in this way is evident from Babylonian clay tablets, several of which far more clearly show map-like 

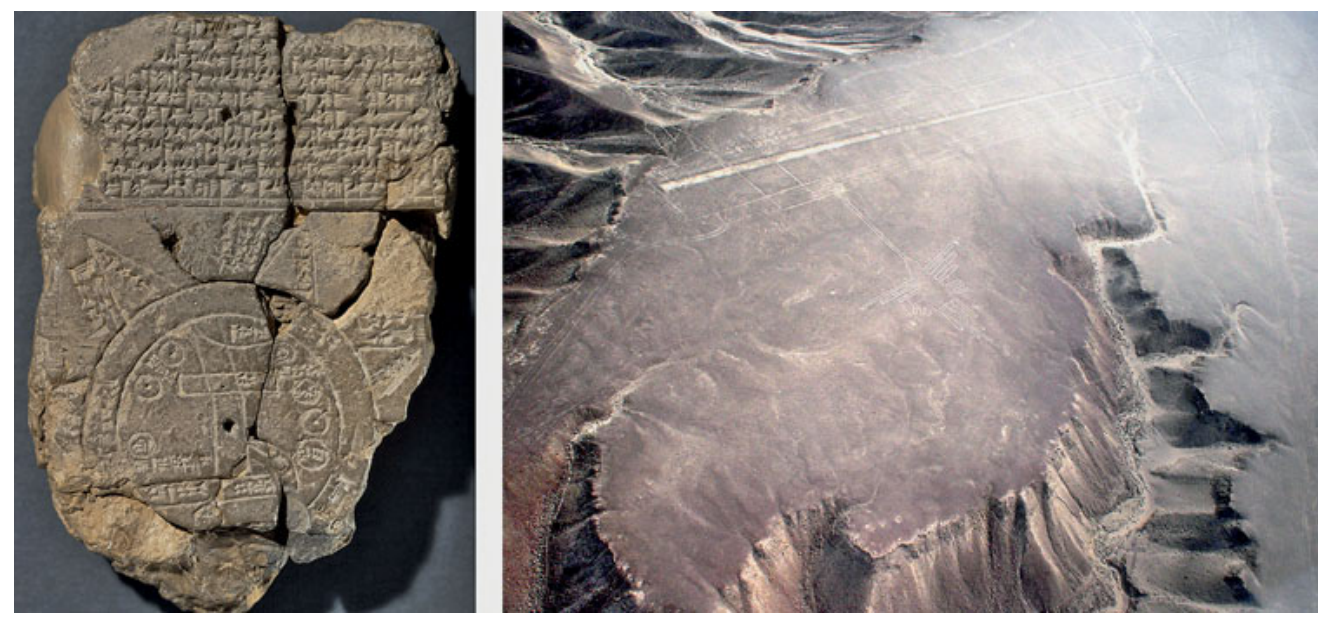

Figure 1 | Two examples of 'map-like' thinking in very different cultures. Left shows a late Babylonian Clay tablet now in the British Museum BM92687 (Photo: The British Museum, used with permission), the right image shows the Hummingbird geoglyph, Nazca Peru, 400-650AD (Photograph: St-Amant made available under Creative Commons License v 3.0, Wikipedia - CC-BY-SA-3.o)

representations of geographic space. These include the late Babylonian 'map of the world' in the British Museum (BM92687) discussed by, for example, Horowitz (I998), which appears to present a mixture of Babylonian cosmology and geography as a map (fig. I, left). Perhaps the clearest example of a Babylonian map is from Nuzi (near Kirkuk, Iran), dating to around 2400 BC. This appears to be a map of the region near Yorghan Tepe (ancient Ga-Sur), but regardless of its geographic attribution it is pretty unambiguously a map of a wide geographic area, bounded by ranges of hills and bisected by a river - possibly the Euphrates - which appears to flow into a delta, then into a lake or sea.

One widely cited candidate for the 'earliest map' was found by Mellaart (I967) at Çatalhüyük, and probably dates from around 6200 BC. It is a painted mural that has previously been interpreted as a plan of around 80 houses and which, if accepted as a map, would show that map-like thinking considerably pre-dated writing. Meece (2006), however, has recently convincingly contested its interpretation as a map and argued that true mapmaking arises only within highly organised, bureaucratic societies. While this may be true of a very formal kind of mapmaking, however, map-like thinking by societies without writing systems is in evidence in the archaeology of some landscapes themselves, perhaps most clearly in the geoglyphs of the Nasca plain, Peru, which include complex geometric figures and animal forms whose shapes cannot be appreciated from the ground (fig. I, right). These are now generally interpreted as pathways and sacred spaces (Aveni 2000; Grün et al. 2003) but regardless of their specific interpretation, they again testify to an ability to imagine the world from above without the need to literally see it and also to a capacity to 'map out' figures and shapes using complex spatial abstraction that is akin to map-making. 
There are good reasons, then, not to uncritically accept the assertion that non-western, non-modern cultures cannot or could not engage in this kind of spatial abstraction. There is also a grave danger that, in seeking to deconstruct specifically modern, western European, ways of thinking, we may end up denying other cultures abilities that we take for granted of ourselves. Ascribing this particular imaginative capacity to the Nasca people has in fact proved so difficult for some 'theorists' that they have found it necessary to ascribe the Nasca geoglyphs to visiting aliens (von Däniken 1998) rather than to acknowledge the sophisticated spatial abilities of native cultures, and it seems possible that the same error is repeated in Thomas' and others' critique, albeit with very different motives. An alternative view would be that the ability to think in a 'map-like' way is one of many cognitive abilities that all humans possess, although it may be expressed in different ways and to different degrees, depending on the environmental, historical and cultural context in which people live out their lives. This does not, of course, deny that cultural differences exist in the ways that this ability is deployed, or even that the way these abilities are deployed may emerge in historically specific contexts and therefore may work either to reinforce or to challenge certain ways of thinking (such as those described by feminist theorists).

Ultimately, however, the argument that the historically-situated nature of map-like thinking somehow invalidates formal spatial analysis and should cause us to move away from maps, plans, orthophotography and GIS is a specious one. Whether or not we adopt the (cognitivist) position that map-like thinking is an innate human ability or the (postmodernist) position that it is a historically-specific 'way of seeing', the spatial organisation of things within a map-like framework exists empirically and can be represented and measured in that way. Analysis of these empirical observations and regularities contributes to our understanding of spatial organisation and behaviour. Where patterns related to visibility and intervisibility occur, such as in communications networks, cities or ritual landscapes, we can document and quantify these regularities as 'visual structure', using graphical methods and statistics. 'Visual structure' is a useful concept because it separates the empirical documentation and quantification of such patterns and regularities from their meaning and interpretation. The question as to why a series of prehistoric tombs, for example, exhibit patterns of visibility or intervisibility is the ultimate purpose of this kind of research, but before we can begin to answer that question we need to show empirically that they exhibit a pattern, and perhaps explore how strong that pattern is. Spatial methods such as 'cumulative viewshed analysis' and 'visibility graph analysis' work because visual structure within landscapes and the built environment has emerged from patterns of human behaviour and meaningful human actions. Crucially, that pattern-formation occurs whether or not those people and communities share the same concept of space that contemporary cartography or GIS uses. To suggest that use of a contemporary spatial framework invalidates formal visibility analysis is therefore the equivalent of declaring that archaeological interpretations that draw on Frankfurt School philosophy are invalid because we have no evidence for Neolithic people reading English translations of Heidegger. 
This critique does, however, have a more positive contribution to make in that it draws attention to the conventions that spatial analysis and GIS use, some of which have become so habitual that we can begin to consider them 'natural' rather than historically-specific. These range from obvious conventions such as the colours and line-styles used for features on maps through 'craft traditions' such as the colour palettes ascribed to elevation models and even to the basic conventions of maps (north is up and the geometry is represented as from above) that we rarely even consider to be conventions. There is a benefit in being forced to confront the culturally specific way we represent space because it reminds us that there are other ways we might choose to do so, and so facilitates the development of new conventions that may open the way to new ways of thinking. One of these new ways is facilitated by the widespread availability of computational methods to represent three dimensional or alternative spatial realities. This is sometimes eschewed as unnecessary, or dismissed as 'technological fetishism' (Huggett 2004) meaning that we do it just because we can, but this is to underestimate the significance of exploring new ways to represent spaces. Rigid abstractions of spaces such as we habitually use in maps, plans and GIS do guide the way that we think about space, and the ability to present results in other forms - which might include transformed spaces, three-dimensional perspective drawings, virtual and augmented realities - is therefore liberating and potentially transformative.

\section{Visualism and archaeology of the senses}

The second critique that has been levelled against spatial analysis of visual structure is that it artificially 'privileges' the visual over other senses, a position which is contrasted with 'archaeologies of the body' or of the senses (e.g. Hamilakis et al. 2002; Skeates 2010), whose goal is to write more holistic accounts of sensory engagements in the past. Frieman and Gillings, for example, claim that those developing visibility studies "have sought to capture and communicate the visual essence of a place or encounter" through ever more complex (view) 'sheds' so that "the shed is increasingly regarded as a valid proxy for perception and visibility a synonym for sensory engagement" (2007, p. 4-5). Taking the position that human perception can only be understood through corporeal engagement, they argue that vision is only one "sensory modality out of many ... from the variety and flow of sensory engagement that characterises the human sensorium" and that a more holistic approach is needed in which "having successfully extracted vision from the sensorium we need to rise to the challenge of putting it back" (2007, p. 5-6). They repeat Ingold's (2000, p. 28I-285) argument that the practice of ordering sensory modalities does not help this goal and that “... the tendency to reify sight as the principal or dominant sense has also provoked comment, in particular accusations of the uncritical and often unthinking visualism".

To some extent, this critique is built on a 'straw man' because little (if any) of the work on visibility analysis makes the claim that it 'represents' or is a 'proxy for' human percep- 
tion as a whole. Most visibility studies clearly understand visibility as only one component of perceptual experience, and they elect to analyse vision either because they find empirical evidence for visual structure within landscapes or the built environment, or because it is more amenable to formal analysis than other sensory modalities, which - at worst - leaves them open to accusations of reductionism or laziness. Nonetheless, it is not unreasonable to question the way in which computational approaches to the sensory structuring of built spaces and landscapes have been dominated by analysis of vision. It is undeniable that, with the exception of a few examples of research into the rôle of sound (such as Mlekuz 2004; Watson and Keating 1999) and occasional attempts to reproduce smells for tourist attractions (Dann and Jacobsen 2003), formal approaches to sensory experience have tended to analyse visual structure rather than auditory, haptic or olfactory patterns, or the ways in which these senses may interact (cf. Papadopoulos and Earl, this volume). It seems entirely plausible that the relative importance given to the visual as a 'dominant' sense is a culturally-specific tendency that has emerged within a particular historical context, and that the perceptual experiences of people in past communities may have been - as some ethnologies suggest - rather different.

Although it is certainly true, however, that "this tendency to elevate vision above all the other sensory modalities has come under sustained attack as part of a broader questioning of the Enlightenment project and its legacy, vision being strongly associated with objective science and Cartesian rationality" (Frieman and Gillings 2007, p. 7), it is also worth at least considering the possibility that the 'dominance' of vision is not just a historical way of thinking but perhaps - as has been argued above for map-like thinking - something that the human brain is inherently predisposed towards. Evidence that vision might be a 'dominant' sense (at least in some rather limited ways) can certainly be found in the way that the senses interact, and can be supported empirically by psychological studies. One familiar example is the 'ventriloquist effect' by which speech that is accompanied by a simultaneous visual stimulus from a different spatial location is perceived as coming from the position of the visual stimulus (Bertelson and Aschersleben I998). In slightly different form, this is also evident in the McGurk effect (McGurk and MacDonald I976), a robust perceptual effect in which subjects are simultaneously shown a video recording of one phoneme (such as 'ga') which has been dubbed over with the sound of a different phoneme (such as 'da'). Subjects consistently report that they perceive the phoneme indicated by the visual stimulus rather than the actual auditory stimulus, and that their auditory perception changes when the conflicting visual stimulus is introduced, suggesting that (at least in this context) the brain tends to 'resolve' conflicts between sound and vision by privileging the visual. Similar evidence also exists for perception that involves visual and haptic senses: experimental evidence suggests that when two objects of equal weight but different sizes are handled, the (visually) largest is usually also perceived to be the heaviest (Flanagan and Beltzner 2000), while Botvinick and Cohen (1998) have shown how subjects report 'feeling' sensations when they see a convincing model of their hand being touched. 
While these examples suggest that visual stimuli are sometimes 'privileged' in sensory processing within the human brain, perhaps more interestingly they also show how the senses are not as separate as we might imagine. If we really wish to understand how the senses relate to one another, therefore, we might also give some consideration to synaesthesia, the condition by which stimulation of one sensory modality is perceived through another. Although research into synaesthesia has quite a long history (e.g. Galton I880; Wheeler and Cutsforth I922; Nielsen 1947), it is not until relatively recently that psychological and cognitive research has established that it has a neurological basis (Simner 20I0). Methods such as fMRI (functional Magnetic Resonance Imaging) have shown how, in many synaesthetes, neuronal activity associated with one 'concurrent' sensual modality is activated by inputs from another 'inducer' modality, resulting in genuinely synaesthetic perception in the subject. This can take many forms, and is not restricted to single inducer $\rightarrow$ concurrent connections. Some of the better documented examples involve 'grapheme $\rightarrow$ colour' synaesthesia, in which numbers are perceived as particular colours and which may be caused by interaction ('cross wiring') in the fusiform gyrus between an area associated with grapheme processing and area $\mathrm{V}_{4}$ (Ramachandran and Hubbard 200ra; Brang et al. 20Ioa). Other well-documented examples relate to 'tone $\rightarrow$ colour' synaesthesia, in which subjects experience colours in response to different musical notes (cf., for example, Crisinel and Spence 20I0; Brougher and Mattis 2005; Beaumont 2004). It may also be the case that synaesthesia - perhaps in less acute forms - is far more common than has been realised within human populations. Recent estimates suggest that around I in 23 people are synaesthetes (Simner et al. 2006), and some have even argued that all humans are born as synaesthetes but that most of us subsequently lose this experience (Cohen Kadosh et al. 2009; Simner et al. 2009). There is also some evidence that it is more prevalent in some sub-populations (notably artists, musicians and poets) than in the general population (Domino I989), and some have speculated that there may be a connection between synaesthesia and the origins and structure of language (Ramachandran and Hubbard 200rb; Simner 2007). Of particular relevance in this context is recent work on 'space $\rightarrow$ time' synaesthesia, which suggests both that this variant is surprisingly common (perhaps more than $2.2 \%$ of the population) and that it may be related in some way to a widespread human ability to learn mappings between arbitrary spatial forms (such as circles) and temporal sequences (Brang et al. 20Iob).

So if we cannot even rigidly separate the senses at a neurological level, we can probably conclude that phenomenology and 'science' are in substantial agreement that the senses are more closely interrelated than has previously been accepted (Stein and Meredith I993), even if there may be some grounds for suggesting that the basic cognitive makeup of human beings may sometimes tend to 'privilege' the visual over other senses. We should therefore acknowledge that the predominance of studies of visibility may indeed be problematic because - with some minor reservations - we cannot assume that humans are 'naturally' visual creatures or that vision is (at least in any simple way) the dominant sensory 
modality. A more interesting line of investigation would therefore lead to the development of methods for exploring how the senses may be related to one another in the structuring of space.

\section{Scale and the senses}

If we largely reject the first accusation that formal spatial analysis is fundamentally flawed because of its use of a historically-situated notion of space, but accept that there is merit in the critique that undue weight has been given to vision to the detriment of a more holistic understanding of sensory engagement, then we need to consider how to begin to establish a theoretical framework that facilitates further development of formal analysis while also allowing us to accommodate a wider consideration of the sensory relationship between space and perception.

This is not simply a case of proposing more methods and case studies, or just broadening the scope of formal analysis to include the exploration of spatial patterns relating to the other senses instead of (or in addition to) vision. Although it may be methodologically challenging in some instances, methods do exist for working with sounds, smells and other sensory modalities. Rather, what is needed is a theoretical basis within which to think about spatial relationships between or merging of sensory modalities. Ideally, this framework should also be relevant both to the built environment and wider landscapes, so as to continue the process of bridging these two disciplinary traditions. To do this, it may be beneficial to refocus the debate onto how the senses operate together during corporeal engagement with the world to generate an experience of place, and how this might translate into spatial patterns in both the built environment and the wider landscape.

In the context of relatively small scales such as might be relevant to the organisation of rooms, households and urban settings, we might turn to what the anthropologist Edward T. Hall termed 'proxemics' (Hall ig66) and which he defined as "the study of how man unconsciously structures microspace - the distance between men in the conduct of daily transactions, the organization of space in the houses and buildings, and ultimately the layout of towns". Establishing the now classic definitions of 'intimate', 'personal', 'social' and 'public' spaces, defined as egocentric 'bubbles' around human subjects (cf. fig. 2), proxemics demonstrated how social interactions are regulated by social norms related to these zones, and posited the existence of culturally-moderated but innate distance-related behaviours in humans. Perhaps surprisingly, in view of its potential utility as a means of understanding the organisation of the built environment, Lawrence and Low were forced to conclude by I990 that "proxemics research in anthropology has been limited" (I990, p. 478) and more generally that "in spite of occasional forays into psychological treatments of human interactions with the built environment, anthropological inquiries into perception and language have not been pursued by later researchers, nor has the development of proxemics 


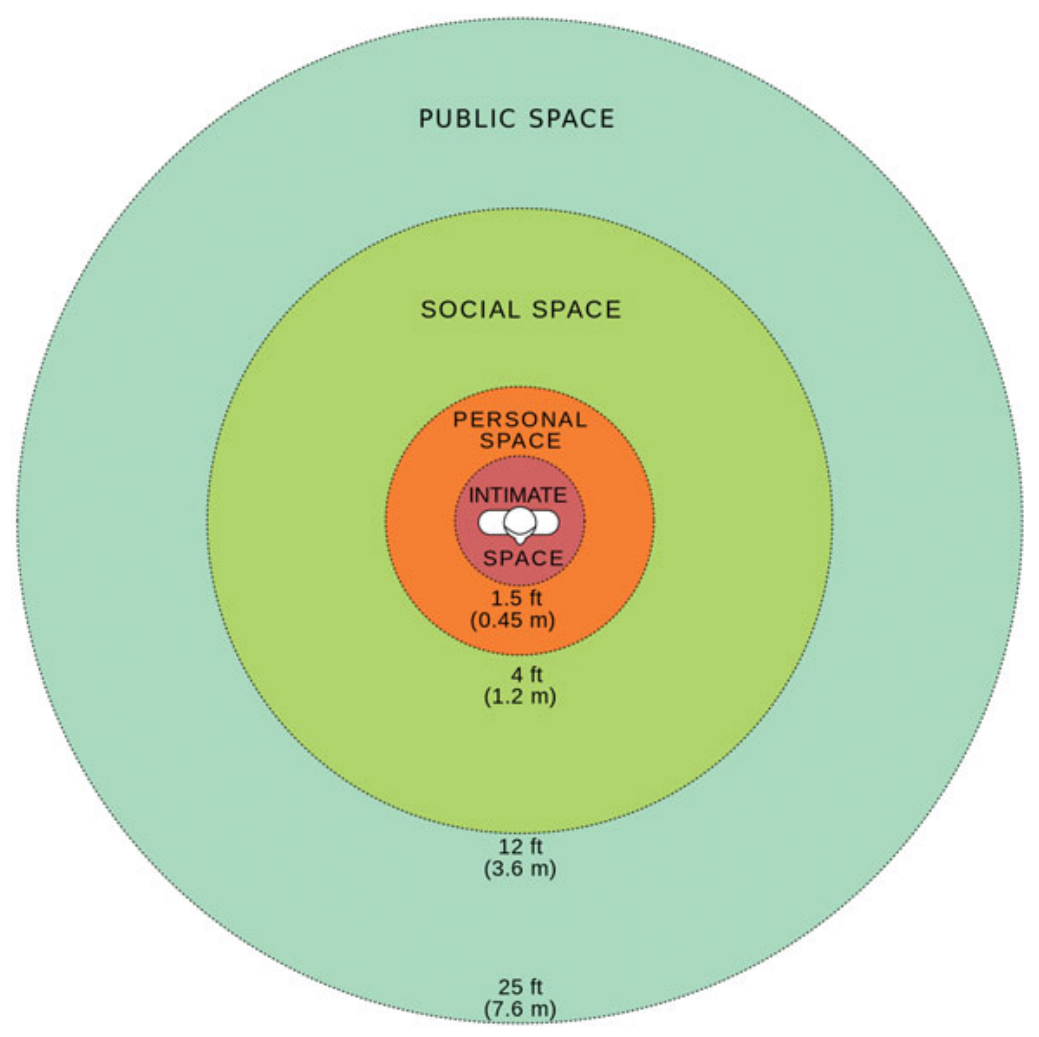

Figure 2 | Hall's (I966) proxemics spaces shown as 'reaction bubbles' (source: Wikimedia Commons).

research been fully explored" (I990, p. 48I). With few exceptions (such as Moore i996), there has been little subsequent attempt to develop proxemic methods within the context of archaeological landscapes or built environments, and postmodern critiques of 'scientific' approaches to the body have tended to follow more phenomenological - and less quantifiable - approaches, with critics such as Farnell arguing that "proxemic zones of space are empty of the dynamically embodied action that structures their meaning" (I999, p. 35I).

If we accept, however, that formal approaches to sensory engagement with the senses are useful (because 'visual structure' can be empirically documented, so it is likely that other 'sensory spatial structure' may also be documented), then proxemics does appear to offer a useful basis for beginning to move beyond spatial methods that are based solely on vision. This is because it recognises the extent to which spatial scale largely controls which senses are implicated in different kinds of social interactions. To put this another way, different spatial scales tend to afford different sensory engagements that we can, admittedly rather crudely, characterise by the different balance of senses that are implicated in such interactions. 
Proxemic methods allow us to recognise - and potentially model - the ways in which different senses are implicated in social interactions at different spatial scales. Social interactions within the 'intimate' space immediately surrounding a person are largely defined by the deployment of touch, smell and even taste (in very intimate interactions) and to some extent hearing in preference to vision. In fact it is common for vision to be intentionally suppressed in intimate social interactions by seeking low-light conditions or closing eyes. Non-intimate intrusions into this space by other social actors (such as greeting kisses, or grooming activities) tend to be tightly regulated by social norms, and unlicensed intrusion can lead to instinctively hostile reactions. Interactions within 'personal space' are characterised by a slightly different combination of visual (particularly 'reading' facial expressions, although these are subject to cultural variation), aural (particularly conversation) and haptic engagement that often takes quite ritualised forms such as handshakes. There is still a component of smell involved, which is often controlled with deodorants and perfumes in contemporary western contexts. Intruding into 'personal space' is, again, closely regulated by social and cultural norms, and although it generally extends around a metre or two from the body, Watson and Graves (1966) and others have shown that this distance also varies with cultural context so that failure of social actors to conform to each other's social expectations can lead to profound misunderstandings. From this, we might expect that spaces designed or evolved to favour intimate or personal interactions will show particular characteristics with respect to all these senses (perhaps through controlled levels of light, smell and so on), and it may be possible to quantify and model these aspects of the built environment in order to infer the likely uses or meanings of different configurations of space. 'Social space' is the zone within which interactions take place between the majority of social actors representing activities such as familial interactions and social negotiations with friends or strangers. Because of the increased distance, these interactions are largely dominated by aural (speech) and visual (gesture, posture and body language) sensory modalities with far less involvement of the other senses. The same applies to 'public' space, which characterises even larger-scale social interactions that often involve many social actors (performances, lectures and speeches, for example). Between them, these various proxemics zones account for distances from around a metre or so away from an individual to perhaps io $\mathrm{m}$ or so although, again, it is reasonable to expect these distances to vary with cultural and historical context.

Beyond this distance, however, proxemics begins to have less to offer. Social interactions over longer distances are - if we exclude technologies such as telephones - rare, and we must therefore consider the way in which other aspects of the world may be perceived by human actors. The 'sense of a place' clearly involves all the senses in a way that a proxemics model may assist with - the experience of being somewhere might incorporate, for example, the feel of the wind on a face, the smell of the soil, the sound of birdsong and the texture of the light. With increasing distance, however, our experience of a place becomes increasingly a function of sound and vision, and ultimately only vision before - at extreme 
distances - we cease to have any sensory experience at all. It is here that the ideas of Higuchi (I988) may be most useful because they provide a framework within which to think about extending proxemics zones out into the wider landscape. This is easiest to explain by reference to the classification of zones within a wooded landscape (I988, p. I2-20), which Higuchi defines in terms of how the senses are implicated in their experience. Thus, he defines a 'short' zone within which each of the trees is recognisable as an individual entity, with leaves and branches. The sound of the rustling leaves and even the smell of the blossom or pollen may be involved in perception at this range, which he suggests extends to a distance equivalent to around 60 times the height of the dominant tree species. Beyond this range he defines a 'medium' zone, within which trees become textural units. The treetops are visible, but not details of individual trees. Significantly, only vision is implicated in the experience of this area of landscape, with mist and haze playing a part in how they are perceived. Beyond a distance equivalent to around IIoo times the height of the dominant species (but depending on the weather) is the 'long' distance landscape in which even the contours of the treetops are no longer perceived. It is possible to perceive (visually) that this part of the landscape is wooded, but not much more, and depth variation within the zone is no longer perceived, so that it can appear flat, like a painted background.

The strength of Higuchi's simple idea is that these landscape zones - like proxemic zones - are defined both by their relationship to the perceiver, the sensory interactions that are possible at different distances, but also by the relationship between perceiver and landscape. These are not abstract spaces which are devoid of cultural meaning or significance, but rather they are what Gibson (I977) would term 'affordances' - they relate solely neither to the subject nor to their environment but to the relationship between them. They therefore offer the possibility of methodological application because they can be modelled and so are amenable to the development of robust, formal methods, while they remain at the same time deeply relational and contextual. What Higuchi's zones afford, say, to the Japanese tradition of landscape design is different from what they afforded to eighteenth century English landscape architecture, just as differences in social norms between cultures mean that proxemic zones afford different social interactions in different cultural contexts.

\section{Conclusions}

This essay is not intended as a concrete proposal for new methods of investigation for either landscape archaeology or the built environment, or as a rallying call to one or other kind of theory. Rather, it is intended as a review of some relevant theoretical discussions about vision/senses/space with the hope that the discussion will firstly facilitate a considered response to the critique that has been levelled at formal visibility analysis, and secondly begin to develop a more coherent, shared understanding of space that might underpin the development of common approaches within the previously divergent disciplinary tradi- 
tions of landscape archaeology and studies of the built environment. Some of the points raised as objections to the use of formal methods for visibility analysis - notably the postmodernist argument about 'map-like' understandings of space - can be rejected, while other aspects of the critique, particularly the accusation that the predominance of visibilityoriented studies has led us to systematically under-research other sensory modalities, should be broadly accepted and even welcomed.

As a response, it has been argued that we look to use the similarities between proxemics and Higuchi's notion of sensually-defined landscape zones, each of which was conceived for a different scale of analysis, in order to establish a more seamless understanding of the relationship between sensory engagement and space which has the potential to bridge the disciplinary divide between 'landscape' and 'built environment'. There are, of course, real differences between sensory engagement in the built environment and with wider landscapes: the first deals, in general, with scales of analysis similar to that of proxemics, so that new approaches and methods should perhaps show much greater consideration of other sensory modalities, particularly in thinking about how buildings, rooms and cities may be structured around complex combinations of senses. At the wider scale of landscape and regional studies, there seems a greater rationale for continuing to investigate vision as the main sensory modality which may structure and organise space in the past because - at least at scales of interaction above several kilometres - vision is the only form of sensory engagement afforded by the landscape at that scale. Of course, it should still be possible to integrate closer zones (such as Higuchi's 'near' landscape) in which other senses play a role, and to explore how - for example - the threshold between the 'hearing' zone and the 'seeing' zone may have been critical in setting out and organising settlements or ritual landscapes.

\section{Bibliographical references}

Aldenfelder, M., and Maschner, H. D. G. (eds.) (1996)

Anthropology, Space and Geographic Information Systems, New York.

Aveni, A. F. (2000)

Between the Lines: The Mystery of the Giant Ground Drawings of Ancient Nasca, Peru, Austin, Texas.

Batty, M. (200I)

"Exploring Isovist Fields: Space and Shape in Architectural and Urban Morphology", in: Environment and Planning B: Planning and Design 28, pp. I23-150.

Beaumont, C. M. (2004)

Musical Synaesthesia in Synaesthetes and Its Manifestation as a Wider Phenomenon [Online]. Sheffield. 
Benedikt, M. L. (1979)

"To Take Hold of Space: Isovists and Isovist Fields", in: Environment and Planning B: Planning and Design 6, pp. 47-65.

Bertelson, P., and Aschersleben, G. (1998)

"Automatic Visual Bias of Perceived Auditory Location", in: Psychonomic Bulletin and Review 5, pp. $482-489$.

Botvinick, M., and Cohen, J. (1998)

"Rubber Hands 'Feel' Touch that Eyes See", in: Nature, 756.

Brang, D., Hubbard, E. M., Coulson, S., Huang, M., and Ramachandran, V. S. (2010a)

"Magnetoencephalography Reveals Early Activation of V4 in Grapheme-Color Synesthesia", in: NeuroImage 53, pp. 268-274.

Brang, D., Teuscher, U., Ramachandran, V. S., and Coulson, S. (20Iob)

"Temporal Sequences, Synesthetic Mappings, and Cultural Biases: The Geography of Time", in: Consciousness and Cognition I9, pp. 3II-320.

Brougher, K., and Mattis, O. (2005)

Visual Music: Synaesthesia in Art and Music Since 1900, London.

Carr, C. (ed.) (1985)

For Concordance in Archaeological Analysis: Bridging Data Structure, Quantitative Technique, and Theory, Kansas City.

Chapman, H. (2006)

Landscape Archaeology and GIS, Stroud.

Clark, D. L. C. (2007)

"Viewing the Liturgy: A Space Syntax Study of Changing Visibility and Accessibility in the Development of the Byzantine Church in Jordan", in: World Archaeology 39, pp. 84-I04.

Cohen Kadosh, R., Henik, A., and Walsh, V. (2009)

"Synaesthesia: Learned or Lost?" in: Developmental Science I2, pp. 484-49I.

Connolly, J., and Lake, M. (2006)

Geographical Information Systems in Archaeology, Cambridge.

Cosgrove, D. (1984)

Social Formation and Symbolic Landscape, London.

Crisinel, A. S., and Spence, C. (2010)

"As Bitter As a Trombone: Synesthetic Correspondences in Nonsynesthetes Between Tastes/ Flavors and Musical Notes", in: Attention, Perception and Psychophysics 72, pp. I994-2002.

Cummings, V., and Whittle, A. W. R. (2004)

Places of Special Virtue: Megaliths in the Neolithic Landscapes of Wales, Oxford.

Dann, G. M. S., and Jacobson, J. K. S. (2003)

"Tourism Smellscapes", in: Tourism Geographies 5, pp. 3-25. 
Domino, G. (1989)

"Synaesthesia and Creativity in Fine Arts Students: An Empirical Look", in: Creativity Research Journal 2, pp. I7-29.

Exon, S., Gaffney, C. F., Woodward, A., and Yorston, R. (2000)

Stonehenge Landscapes: Journeys Through Real-and-Imagined Worlds, Oxford.

Farnell, B. (1999)

"Moving Bodies, Acting Selves", in: Annual Review of Anthropology 28, pp. 34I-373.

Flanagn, J. R., and Beltzner, M. A. (2000)

"Independence of Perceptual and Sensorimotor Predictions in the Size-Weight Iillusion", in:

Nature Neuroscience 3, pp. 737-74I.

Frieman, C., and Gillings, M. (2007)

“Seeing is Perceiving?", World Archaeology 39, pp. 4-16.

Gaffney, V., and Stančič, Z. (I99I)

GIS Approaches to Regional Analysis: A Case Study of the Island of Hvar, Ljubljana.

Gaffney, V., Stančič, Z., and Watson, H. (1996)

"Moving from Catchments to Cognition: Tentative Steps Towards a Larger Archaeological Context for GIS." in: M. Aldenderfer and H. D. G. Maschner (eds.), Anthropology, Space and Geographic Information Systems, New York.

Galton, F. (1880)

Visualised Numerals, in: Nature 22, pp. 494-495.

García Sanjuan, L., Metcalfe-Wood, S., Rivera Jiménez, T., and Wheatley, D. (2006)

"Análisis de pautas de visibilidad en la distribución de monumentos megalítos de Sierra Morena occidental”, in: I. Grau Mira (ed.) La aplicación de los SIG en la arqueología del paisaje, Alicante, pp. I8I-200.

García Sanjuan, L., and Wheatley, D. (eds.) (2002)

Mapping the Future of the Past, Seville.

Gibson, J. J. (1977)

"The Theory of Affordances", in: Perceiving, Acting and Knowing: Toward an Ecological Psycholog, pp. 67-82.

Gibson, J. J. (1979)

The Ecological Approach to Visual Perception, Boston.

Gidlow, J. (2000)

"Archaeological Computing and Disciplinary Theory", in: G. Lock and K. Brown (eds.), On the Theory and Practice of Archaeological Computing, Oxford, pp. 23-30.

Gillings, M., Mattingly, D., and Van Dalen, J. (eds.) (1999)

Geographic Information Systems and Landscape Archaeology, Oxford.

Gillings, M., and Wheatley, D. (200I)

"Seeing is Not Believing: Unresolved Issues in Archaeological Visibility Analysis", in: B. Slapsak (ed.), On the Good Use of Geographic Information Systems in Archaeological Landscape Studies, Brussels, pp. 25-36. 
Grau Mira, I. (ed.) (2006)

La aplicación de los SIG en la arqueología del paisaje, Alicante.

Grün, A., Sauerbier, M., and Lambers, K. (2003)

"Visualisation and GIS-based Analysis of the Nasca Geoglyphs", in: M. A. S. Doerr (ed.), The Digital Heritage of Archaeology - Proceedings of the zoth CAA Conference, Heraklion, Crete, April 2002, Athens, pp. I6I-I67.

Hall, E. T. (1966)

The Hidden Dimension, Garden City, N.Y.

Hamilakis, Y., Pluciennik, M., and Tarlow, S. (2002)

Thinking Through the Body: Archaeologies of Corporeality, New York, London.

Haraway, D. J. (199I)

Simians, Cyborgs, and Women: The Reinvention of Nature, New York.

Harley, J. B., and Woodward, D. (1987)

The History of Cartography. Vol. 1: Cartography in Pre-Historic Ancient and Medieval Europe and the Mediterranean, Chicago, London.

Higuchi, T. (1988)

The Visual and Spatial Structure of Landscape, Massachusetts.

Hillier, B., and Hanson, J. (1984)

The Social Logic of Space, Cambridge, MA.

Hodder, I. (200I)

Archaeological Theory Today, Cambridge, MA.

Horowitz, W. (1998)

Mesopotamian Cosmic Geography, Winona Lake, Ind.

Huggett, J. (2004)

"Archaeology and the New Technological Fetishism", in: Archeologia e Calcolatori I5, pp. 8I-92.

Hunt, E. D. (1992)

"Upgrading Site-Catchment Analyses With the Use of GIS: Investigating the Settlement Patterns of Horticulturalists", in: World Archaeology 24, pp. 283-309.

Ingold, T. (2000)

The Perception of the Environment: Essays in Livelihood, Dwelling and Skill, London.

Johnson, I., and North, M. (eds.) (1997)

Archaeological Applications of GIS: Proceedings of Colloquium II UISPP, XIIIth Congress, Forli, Italy, September 1996, Sydney.

Johnson, M. (1999)

Archaeological Theory: An Introduction, Oxford, UK.

Jones, A. (200I)

Archaeological Theory and Scientific Practice, Cambridge, MA. 
Kvamme, K. L. (1983)

A Manual for Predictive Site Location Models: Examples from the Grand Junction District, Colorado, Colorado, Grand Junction District.

Kvamme, K. L. (1989)

"Geographical Information Systems in Regional Archaeological Research and Data Management”, in: M. B. Schiffer (ed.), Archaeological Method and Theory, Tuscon, Arizona, pp. 139-203.

Lawrence, D. L., and Low, S. M. (1990)

"The Built Environment and Spatial Form", in: Annual Review of Anthropology I9, pp. 453-505.

Llobera, M. (1996)

"Exploring the Topography of Mind: GIS, Social Space and Archaeology", in: Antiquity 70, pp. 612-622.

Llobera, M. (1999)

Landscapes of Experiences in Stone: Notes on a Humanistic Use of a Geographic Information System (GIS) to Study Ancient Landscapes, Oxford.

Llobera, M. (2003)

"Extending GIS-based Visual Analysis: The Concept of Visualscapes", in: International Journal of Geographical Information Science I7, pp. 25-48.

Lock, G. R. (ed.) (2000)

Beyond the Map: Archaeology and Spatial Technologies, Amsterdam.

Lock, G. R., and Stančič, Z. (eds.) (1995)

Archaeology and Geographical Information Systems: A European Perspective, London.

Maschner, H. D. G. (ed.) (1996)

New Methods, Old Problems: Geographical Information Systems in Modern Archaeological Research, Carbondale, Ilinois.

McGurk, H., and MacDonald, J. (1976)

"Hearing Lips and Seeing Voices", in: Nature 264, pp. 746-748.

Meece, S. (2006)

“A Bird's Eye View - of a Leopard's Spots. The Çatalhöyük 'Map' and the Development of Cartographic Representation in Prehistory”, in: Anatolian Studies 56, pp. I-I6.

Mellaart, J. (1967)

Çatal Hüyük: A Neolithic Town in Anatolia, London.

Mlekuz, D. (2004)

"Listening to Landscapes: Modelling Past Soundscapes in GIS", in: Internet Archaeology I6, http://intarch.ac.uk/journal/issueı6/mlekuz_index.html (I2 May 20I2).

Moore, J. D. (1996)

"The Archaeology of Plazas and the Proxemics of Ritual: Three Andean Traditions", in: American Anthropologist 98, pp. 789-802. 
Nielson, J. M. (1947)

"Sensory Perception Through Vision, a Synesthesia. Report of Case", in: Bulletin of the Los Angeles Neurological Society I2, p. I95.

Paliou, E. (2009)

The Visual Consumption of Mural Painting in Late Bronze Age Akrotiri (Thera, Greece): A Computational Approach to Visibility Analysis in Three-Dimensional Built Environments, Southampton (PhD thesis, unpublished).

Paliou, E., and Wheatley, D. (2007)

"Integrating Spatial Analysis and 3D Modelling Approaches to the Study of Visual Space: Late Bronze Age Akrotiri", in: The World is in Your Eyes - Proceedings of the XXXIII Computer Applications in Archaeology Conference, 21-24 March 2005, Tomar, Portugal, pp. 375-386.

Ramachandran, V. S., and Hubbard, E. M. (2001a)

"Psychophysical Investigations into the Neural Basis of Synaesthesia", in: Proceedings. Biological Sciences / The Royal Society 268, pp. 979-983.

Ramachandran, V. S., and Hubbard, E. M. (200Ib)

"Synaesthesia -A Window into Perception, Thought and Language", in: Journal of Consciousness Studies 8, pp. 3-34.

Simner, J. (2007)

"Beyond Perception: Synaesthesia as a Psycholinguistic Phenomenon", in: Trends in Cognitive Sciences II, pp. 23-29.

Simner, J. (2010)

"Defining Synaesthesia", in: British Journal of Psychology, pp.I-I5.

Simner, J., Harrold, J., Creed, H., Monro, L., and Foulkes, L. (2009)

"Early Detection of Markers for Synaesthesia in Childhood Populations", in: Brain: A Journal of Neurology 132, pp. 57-64.

Simner, J., Mulvenna, C., Sagiv, N., Tsakanikos, E., Witherby, S. A., Fraser, C., Scott, K., and Ward, J. (2006)

"Synaesthesia: The Prevalence of Atypical Cross-Modal Experiences", in: Perception 35, pp. I024-I033.

Skeates, R. (2010)

An Archaeology of the Senses: Prehistoric Malta, Oxford.

Stavroulaki, G., and Peponis, J. (2005)

"Seen in a Different Light. Icons in Byzantine Museums and Churches", in: Nes, A. (ed.), Proceedings. 5th International Symposium on Space Syntax, Delft. http://www.spacesyntax. tudelft.nl/media/longpapers2/giannastavroulaki.pdf (27 May 20I2).

Stein, B. E., and Meredith, M. A. (1993)

The Merging of the Senses, Cambridge, MA.

Thomas, J. (199I)

Rethinking the Neolithic, Cambridge. 
Thomas, J. (1993)

"The Politics of Vision and the Archaeologies of Landscape", in: B. Bender (ed.), Landscape, Politics and Perspectives. Oxford, pp. 19-48.

Thomas, J. (1996)

Time, Culture and Identity: An Interpretive Archaeology, London.

Thomas, J. (1999)

Understanding the Neolithic, London.

Thomas, J. (200I)

"Archaeologies of Place and Landscape", in: I. Hodder (ed.) Archaeological Theory Today, Cambridge, pp. 165-186.

Tilley, C. (1994)

A Phenomenology of Landscape: Places, Paths and Monuments, Oxford.

Trick, S. (2004)

"Bringing it All Back Home: The Practical Visual Environments of Southeast European Tells", in: Internet Archaeology I6, http://intarch.ac.uk/journal.issuer6/trick_index.html (I5 May 20I2).

Trigger, B. (1989)

A History of Archaeological Thought, Cambridge.

Turner, A., Doxa, M., O'Sullivan, D., and Penn, A. (200I)

"From Isovists to Visibility Graphs: A Methodology for the Analysis of Architectural Space", in: Environment and Planning B: Planning and Design 28, pp. I03-І2г.

Von Däniken, E. (1998)

Arrival of the Gods: Revealing the Alien Landing Sites at Nazca, Shaftesbury.

Watson, A., Keating, D. (1999)

"Architecture and Sound: An Acoustic Analysis of Megalithic Monuments in Prehistoric Britain”, in: Antiquity 73, pp. 325-336.

Watson, O. M., and Graves, T. D. (1966)

"Quantitative Research in Proxemic Behavior", in: American Anthropologist 68, pp. 97I-985.

Westscott, K. L., and Brandon, R. J. (eds.) (2000)

Practical Applications of GIS for Archaeologists: A Predictive Modeling Kit, London.

Wheatley, D., and Gillings, M. (2000)

"Vision, Perception and GIS: Developing Enriched Approaches to the Study of Archaeological Visibility”, in: G. R. Lock (ed.), Beyond the Map: Archaeology and Spatial Technologies, NATO Science Series A: Life Sciences vol 32I, pp. I-27 Amsterdam.

Wheatley, D., and Gillings, M. (2002)

Spatial Technology and Archaeology: A Guide to the Archaeological Applications of GIS, London.

Wheeler, R. H., and Cutsforth, T. D. (1922)

The Synaesthesia of a Blind Subject With Comparative Data from an Asynaesthetic Blind Subject, Eugene. 